\title{
Assessment of Runoff, Sediment Yields and Nutrient Loss Using the Swat Model in Upper Indus Basin of Pakistan
}

\author{
Washakh Rana Muhammad Ali1,2,3,4, Ningsheng Chen $1^{*}$, Waque Rana Muhammad Umar5, \\ Almas Sundas ${ }^{6,7}$, Zaib-Un-Nisa ${ }^{8}$, Rahman Mahfuzur ${ }^{1,2,9}$
}

${ }^{1}$ Key Laboratory of Mountain Hazards and Surface Process, Institute of Mountain Hazards and Environment, Chinese Academy of Sciences, Chengdu, China

${ }^{2}$ University of Chinese Academy of Sciences, Beijing, China

${ }^{3}$ School of Architecture, Neijiang Normal University, Neijiang, China

${ }^{4}$ Institute of Tibetan Plateau Research, Chinese Academy of Sciences, Beijing, China

${ }^{5}$ School of Management, Northwestern Polytechnical University, Xi'an, China

${ }^{6}$ Key Laboratory for Space Biosciences \& Biotechnology, School of Life Sciences, Northwestern Polytechnical University, Xi'an, China

${ }^{7}$ Key Laboratory for NeuroInformation of Ministry of Education, School of Life Science and Technology, University of Electronic Science and Technology of China, Chengdu, China

${ }^{8}$ College of Earth and Environmental Sciences, University of the Punjab, Lahore, Pakistan

${ }^{9}$ Department of Civil Engineering, International University of Business Agriculture and Technology, Dhaka, Bangladesh

Email: washakh@qq.com, *chennsh@imde.ac.cn, umar.waque@hotmail.com, sundas.almas@outlook.com,

mfzrahman@iubat.edu

How to cite this paper: Ali, W. R. M., Chen, N. S., Umar, W. R. M., Sundas, A., Zaib-Un-Nisa, \& Mahfuzur, R. (2020). Assessment of Runoff, Sediment Yields and Nutrient Loss Using the Swat Model in Upper Indus Basin of Pakistan. Journal of Geoscience and Environment Protection, 8, 62-81.

https://doi.org/10.4236/gep.2020.89004

Received: June 27, 2020

Accepted: September 6, 2020

Published: September 9, 2020

Copyright $\odot 2020$ by author(s) and Scientific Research Publishing Inc. This work is licensed under the Creative Commons Attribution International License (CC BY 4.0).

http://creativecommons.org/licenses/by/4.0/

\begin{abstract}
The main objective of this study is to understand the runoff, sediment yield and water quality of the Upper Indus River Basin of Pakistan. To achieve this goal, specific objectives have been met which include, setup of a hydrological model using Soil and Water Assessment Tool (SWAT) then calibration and validation of the hydrological model using river discharges and in the end investigating the performance of the hydrological model by SWAT. This research will have great impacts on socio-economic conditions of Pakistan because study of upper Indus River basin is imperative to provide data needed for its management, and to warrant that it is sustainable to support the increasing population and conservational flows. A set of programmable mapping components MapWindow Geographic Information System (GIS) was used which is an open source GIS based mapping application. It is SWAT used spatially distributed information on elevation, land use, slope and soil. The program Sequential Uncertainty Fitting ver.2 (SUFI-2) in a combination of uncertainty analysis and calibration of outputs was used in SWAT-CUP. SWAT model used input data, which have climate information to obtain results. The observed climate data of temperature gauges and rain gauge were
\end{abstract}


used as input in the SWAT model; the calibration results for three discharge stations were produced. The initial $P$-factor value was satisfactory but more iteration to attempt narrow uncertainty band with improving goal function, resulted in small percentage of observed data within uncertainty band. A warm up period of three years (1979-1982) was used for simulation of SWAT model. The model was calibrated for selected three catchments for the period 1982-2000 and validated for period 2001-2010. Results are quite comparable with the observed flows.

\section{Keywords}

Sediment Transport, Runoff, GIS, SWAT Model, Hydrological Modelling, Nutrient Loss

\section{Introduction}

Pakistan is a developing country and its population is, according to World Bank (2012), 179.2 million from which, about $76 \%$ of total population lives in the rural areas. The economy is based on agriculture and vastly dependent on irrigation system of Indus River (Snow, 1990). 100 MAF of water consumed annually from 40 million acres irrigated area, which gives $70 \%$ of runoff of river by total (WAPDA, 1990). According to Kahlown (Kahlown, Raoof et al., 2007), the availability of water per capita since 1947 has been decreased from $5600 \mathrm{~m}^{2}$ to $1000 \mathrm{~m}^{2}$. The Indus River arises from the Hindu Kush, Karakoram and the Himalayan regions of Pakistan, flowing south towards the Arabian Sea. The Indus River forms a link between groundwater of the Punjab and Sindh Provinces and the glaciers and snow in the mountains. In addition, Pakistan has the highest ratio of the irrigation through rainfall. Indus River Irrigation System (IRIS) has 3 major storage reservoirs, 43 main canals and 19 barrages. Total length of irrigation system is $57,000 \mathrm{~km}$ and 89,000 watercourses. This irrigation system provides water to farmland of 15 million hectares (IRIN December 31 2001).

The irrigation systems have significant impacts on the environment. These systems, by abstracting water in high quantity from rivers leave insufficient flow, which is not enough to meet the needs of downstream ecosystems. Upstream abstraction of water in large quantity has high impact on coastal regions as well as marine regions. The allocation of water is favored by dominant developments at large scale like commercial uses, development of reservoirs, dams, ecosystems and irrigation system and hydropower projects 2001.

The Indus River flows through most of Pakistan and it is the 12th largest river in the world. Pakistan is reliant on Indus River as a main source of water. Indus River is a trans-boundary river shared by India. The dense population of Pakistan requires water availability to increase; however, the amount of water supplied from the Indus River is no longer abundant to fulfil the requirement. Over-use of groundwater in many regions is causing the quality and availability to drop. Although, groundwater covers for about $40 \%$ of the irrigation require- 
ments in this region, the Indus River supplies drinking water to 130 million people, produces electricity and covers the water deficit in the irrigation requirement. In addition, dams on the main tributary of Indus River generate $45 \%$ of the total electrical energy for Pakistan. In other words hydrological management is of crucial importance for the socio-economic status of Pakistan.

And when we talk about runoff, sediment yield and water quality in hydrological modelling SWAT model is well used by the researchers around the world (Arnold, Moriasi et al., 2012; Francesconi, Srinivasan et al., 2016). The popularity of SWAT is because it uses Geographic Information System (GIS) as interface which make it easy to calibrate and validate. Basic GIS data is online and freely available that is required for SWAT model. In this paper, the author aim is to discuss the SWAT modelling and problem description in 15 highland of Nile Basin countries. Many methods are used to find out the model performance, model set-up, model parameters presentation in physical form, and the hydrological model balance. Many indicators are set to describe the performance and because of that it is noted that SWAT model shows satisfactory to very good results. Some papers about Nile Basin also reported unrealistic parameter values. But most of paper lacks such kind of information. This is the basic reason that positive evaluation is very difficult in overall study of SWAT model. There is also a gap of less information about crops and vegetation land use process. To get very good results of evapotranspiration, generation of runoff and computation of erosion, a proper simulation is required. It is also found that different software version of SWAT showed different results for similar case. The main recommendation for good evaluation is that the research papers should provide more details about model setup, model output and parameters (Arnold, Moriasi et al., 2012). Therefore, this research is of great importance referring to the limitations and gap in the current practices with SWAT modelling.

SWAT model is spatially distributed and continuous time GIS interface (Arnold, Srinivasan et al., 1998), which is designed to simulate sediment process, nutrient amount, water quality and quantity and transport of pesticide at a catchments level on a daily time step. In SWAT, hydrologic response units (HRUs) are used that are based on specific soil type, slope characteristics of an area and use of land. The HRUs describe spatial heterogeneity in terms of, specific soil type, slope and land cover characteristics within a watershed area. Different hydrologic components including evapotranspiration, surface runoff, and peak rate of groundwater flow, runoff and sediment yield for each HRU unit were estimated by model. This research will have great impacts on socio-economic conditions of Pakistan because the study of upper Indus River basin is imperative to provide data needed for its management, and to warrant that it is sustainable and capable to support the increasing population and conservational flows.

\section{Materials and Methods}

\subsection{Study Area and Data Used}

The Indus River has many tributaries shown in Figure 1. Area of Indus river 


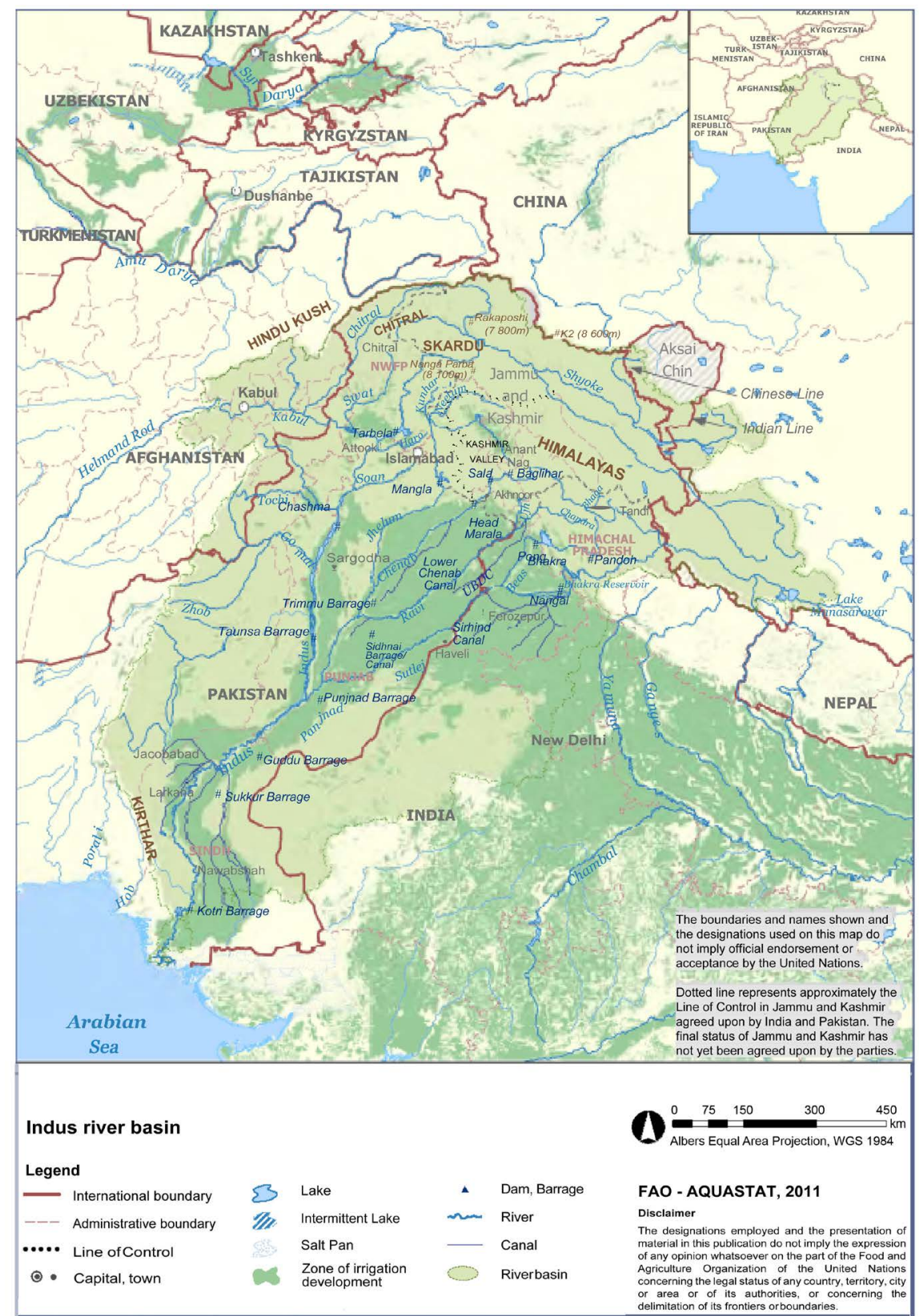

Figure 1. Indus river basin (Aquastat, 2011).

basin is $970,000 \mathrm{~km}^{2}$. However, this study is confined only to Tarbela reservoir to Kalabagh at Indus River that lies between the Upper Indus Basin (UIB) (NESPAK, 1997). Hunza, Shyok, Astore and Gilgit rivers are major tributaries of upper Indus River Basin. Indus River discharge is because of melting glaciers and snowmelt because of seasonal change. River discharge increased because of increase in temperature in summer season. Snow covers $80 \%$ of Upper Indus basin including $1 / 4$ forest area with have no major lakes (Snow, 1990). Tectonically active order is present beneath Indus River (Seeber \& Gornitz, 1983) and because of this it has threat of floods caused by landslides and rockslides (Hewitt, 2005). Streams are blocked by glaciers which cause floods and block natural reservoirs 
(Hewitt, 2005).

The Haro River originates at 9217 feet above mean sea level (AMSL) near Moshpuri village. It flows through the southern side of the Moshpuri hills and then follows east to west direction till it reaches the foothills at Malachh, where it is linked by several small streams around Nathia Galli. The surrounding mountains are as high as 9000 feet (AMSL) and remain snow covered for a major part of the year. At higher elevations, these hills are generally dominated by pine trees with patches of shrubs at the downstream. The overburden on these hills is mostly clay mixed with boulders and stones. From Malachh onwards the overall course of the river flow is from northeast to southwest direction. At the Khanpur dam site, the Haro River flows through an area, which is roughly rectangular in shape with a length of nearly 54 miles and an average width of 14 miles. The overall flow direction is northwest from its origin to Khanpur Dam. Further, it drains through parts of Punjab, Khyber Pakhtunkhwa and the North West Frontier Province (NWFP) of Pakistan. Its coordinates are 33.7689 and 72.2453 (in Decimal Degrees) or $33^{\circ} 46^{\prime} 8^{\prime \prime} \mathrm{N}$ and $72^{\circ} 14^{\prime} 43^{\prime \prime E}$ in DMS (Degrees Minutes Seconds). The reduction in inflows of Khanpur dam from Haro River causes water scarcity in the surrounding communities during summer season.

The Haro River is fed by four major tributaries:

- The Neelan, rising in the Nara Hills;

- The Lora Haro, rising in the Murree Hills around Lora;

- The Kunhad, flows through the area of Dubran and Siribang;

- The Stora Haro, rising in the GaliatMalach hills (Both SatoraHaro and Lora Haro merge at Dotara near Jabri).

The Indus River depletes through the greater part of Pakistan and it is the $12^{\text {th }}$ biggest waterway on the planet thus, Pakistan is subject to Indus River as a noteworthy wellspring of water supply. The Indus River has numerous tributaries appeared in Figure 1. Region of Indus stream bowl is $970,000 \mathrm{~km}^{2}$. Be that as it may, this research is bound just to Tarbela store to Kalabagh at Indus River that lies between the Upper Indus Basin (UIB) (NESPAK, 1997). Hunza, Shyok, Astore and Gilgit streams are significant tributaries of upper Indus River Basin.

If the water availability in the basin is below $1700 \mathrm{~m}^{3}$ per capita then it is the condition of water scarcity. World Bank forecasted that the water stress threshold level for Pakistan is already low, which in 2035 will reach to a situation of water scarcity. World Bank estimated the high value of surface and groundwater availability, and a lower population size (United Nations, 2009; "Population Division of the Department of Economic and Social Affairs").

Per capita availability of water in a population indicates the increase rate of population and its water consumption as compared to water supply. Population growth continuously becomes high. From 1950 to 1980, Pakistan's population grew high i.e. from 40 million to over 80 million and 185 million was estimated in 2010 (United Nations, 2009; "Population Division of the Department of Economic and Social Affairs).

The quality of water of Indus Basin Irrigation System (IBIS) is excellent. Ac- 
cording to Bhutta (Bhutta, 1999) safe use of water should have Total Dissolved Solids (TDS) range between $62-374 \mathrm{ppm}$. During high flow, the TDS in the upper streams is $60 \mathrm{ppm}$ and during low flow, it reached $200 \mathrm{ppm}$. Water quality degenerate downstream but is in required range, as TDS at Kotri barrage ranges from 150 to $374 \mathrm{ppm}$.

In the 1990s, heavy flood caused water logging in the area of IBIS, in 2000-2010 droughts in this area lowered water table level and a reduction in water logging rate. Presently, around 7 million ha area is water logged and saline. In 1990s, many of the Pakistan-Salinity Control and Reclamation (SCARP) Transition Pilot Project tube wells (Linn) were disregard and farmers installed shallow tube wells in field (Zaman \& Ahmad, 2009).

\subsubsection{Soil Data}

Soil maps are very important to define HRUs. The United Nations Educational, Scientific and Cultural Organization (UNESCO)/Soil Map of The Food and Agriculture Organization of the United Nations (FAO) was used at the scale of 1:5 million by (FAO/UNESCO). Organic carbon content, $\mathrm{pH}$ and soil moisture storage capability were derived from these soil maps.

\subsubsection{Digital Elevation Model (DEM)}

The 90 DEM Shuttle Radar Topographic Mission (SRTM) is collected from the Consortium for Spatial Information (CGIAR-CSI) (Jarvis, Reuter et al., 2008; Trabucco \& Zomer, 2010). The SRTM digital elevation data, were produced by National Aeronautics and Space Administration (NASA) (SRTM).

\subsubsection{Land Use}

In a watershed, land use has strong effects on evapotranspiration, surface erosion and runoff. In present study land use/land cover maps of $400 \mathrm{~m}$ resolution at the equator are developed from USGS Global Land Cover Characterization (GLCC) database (De Fries et al., 1998).

\subsubsection{Weather Data}

Weather data for study is originated from the Global Summary of the Day (GSOD) of the USA's National Climatic Data Centre (NCDC). Weather data is from 1979 to 2010 . The daily elements included in the Weather data of required weather stations are:

- Temperature $\left({ }^{\circ} \mathrm{C}\right)$;

- Precipitation $(\mathrm{mm})$;

- Wind $(\mathrm{m} / \mathrm{s})$;

- Relative Humidity (fraction);

- $\operatorname{Solar}\left(\mathrm{MJ} / \mathrm{m}^{2}\right)$.

\subsection{Research Model Analysis}

Hydrological modelling of Haro River required SWAT, which was used with the SUFI-2 for calibration, validation, and uncertainty analysis. The softwares used 
for this research were:

- MapWindow GIS;

- SWAT 2009;

- MWSWAT 2009;

- SWAT-CUP4;

- SUFI-2.

\subsubsection{MapWindow GIS}

MapWindow GIS is an open source GIS based mapping application including a set of programmable components. United States Environmental Protection Agency (US EPA) adopted it as the main GIS platform for Point and Nonpoint Sources Science Integrating watershed modelling and analysis software (Johnston, McGarvey et al., 2011). It is an extensible GIS with data editors, models and hot-link handlers etc.

\subsubsection{SWAT 2009}

SWAT requires spatially distributed information on land use, slope, elevation and soil (Arnold, Srinivasan et al., 1998). SWAT also requires weather data including temperature and rainfall, crop characters and managing practices for calculating the crop yields in different HRUs of the river basin as well as hydrology. SWAT Program is a time continuous, semi-distributed for watershed, which works on daily data. SWAT Hydrological model is developed for the assessment of water supplies, agricultural chemical yields, and sediment in watersheds and larger river basins. SWAT model is semi-physically based model because it divides a large basin into small sub-basins, which have high spatial data. The major components of SWAT are:

- Plant growth;

- Hydrology;

- Weather;

- Stream routing;

- Erosion;

- Nutrients;

- Pesticides;

- Land management.

Spatial detail and parameterization of a watershed was done by dividing a basin into sub-basins. These sub-basins are further subdivided into many HRUs based on specific elevation, land use, soil, and slope characteristics. Nutrient transformations of every HRU and water losses were described individually for relevant sub-basin. The equation used in SWAT is soil and water balance in a catchment area. The simulated processes include:

- Lateral flow;

- Infiltration;

- Surface runoff;

- Plant water uptake;

- Evaporation; 
- Percolation to shallow and deep aquifers.

Soil Conservation Service Curve Number (SCS-CN) was used in equation to define surface runoff of catchment with land use, soil cover, daily precipitation data and soil moisture characteristics (Mishra \& Singh, 2013).

\subsubsection{MWSAWT}

MWSWAT 2009 (MapWindow Interface for SWAT) is a plug-in for MapWindow. MWSWAT provides the same functionality as Arc SWAT.

\subsubsection{SWAT-CUP}

SWAT-CUP is an interface and was developed for SWAT. The main function of SWAT-CUP is to maintain a strong connection between the input and output file of a model and the calibration process. In present study, SUFI-2 was used as a calibration program. Using this interface, any sensitivity program or calibration/uncertainty can easily be linked to SWAT. Automated model calibration required that the parameters of uncertainty were extracted and updated from the output files while the model was run. A schematic of the linkage between SWAT and SUFI-2 is illustrated in Figure 2.

\subsubsection{SUFI-2 (the Calibration Program)}

The program SUFI-2 is a combination of uncertainty analysis and calibration of outputs. In any hydrological modelling, the uncertainties may occur in input, conceptual model, model parameters and in the measured data, which can be removed by Calibration. SUFI-2 program measures the present uncertainties and calibrate the model to obtain the smallest parameter uncertainty ranges for good calibration results.

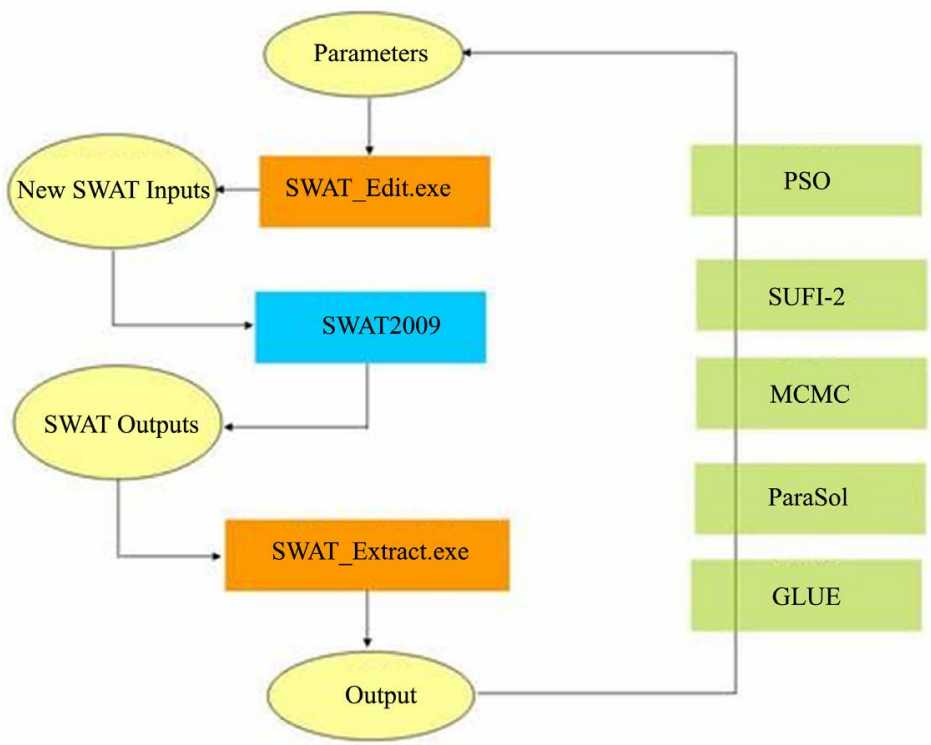

Figure 2. Schematic linkages between SWAT and Sequential Uncertainty Fitting ver.2 (SUFI-2), where Particle Swarm Optimization (PSO), Markov Chain Monte Carlo (MCMC), Parameter Solution (ParaSol), and Generalized Likelihood Uncertainty Estimation (GLUE) algorithm to SWAT model were used. 


\subsection{Model Setup}

\subsubsection{Data Preparation}

The DEM was used to delineate the watershed area and make the drainage patterns of terrain. DEM mask is an image, which was used to superimpose on the DEM.

\subsubsection{Watershed Delineation}

Delineation of watershed is a plug-in in MapWindow to delineate the watershed. This is useful in modelling and watershed characterization. In a watershed delineation, we subdivided the watershed into sub-basins. Watershed Delineation tools define multiple hydrological connected sub-watersheds within a given study area. These tools provide flexibility in editing attributes and shapes of delineated watersheds and outlets, and in generating stream networks. The Watershed Delineation tools define and create a boundary around the entire land area contributing to flow in a stream.

\subsubsection{HRU Definition}

In hydrological modelling SWAT uses the HRUs. HRUs may be formed per sub-basin, or may be more than one in each basin depending on the specific elevation and topology of that basin. HRUs form the detailed database merge maps from soil and land use maps.

\subsubsection{SWAT Setup and Run}

In SWAT setup, the program files read the meteorological data and input data, SWAT files are written in specific pattern, these newly written files are processed in model to get the output files. The SWAT Setup and Run require weather station, precipitation, temperature and humidity details, we chose the period of simulation for 32 years because the collected data was for this range and warm up period of 3 years was used to check and compare the initial results. We can also rewrite SWAT input or add details by the use of SWAT Editor tool, after re editing SWAT input, model can be run and output files can be generated, lastly, the output from the SWAT run can be saved.

\section{Results and Discussion}

Figures (Figures 3-13) for Haro River basin, show the calibration (1982-2000) and validation (2000-2010) results for three discharge stations. A warm up period of three years (1979-1982) was used for simulation of SWAT model.

The water yield in Figure 8 shows large uncertainties in the water yield of water rich sub-basins. The reported uncertainty contains natural year-to-year variation due to climate as well as water abstraction and water use.

Based on statistical analysis, the assessment shows that SWAT model had a decent performance for calibration and validation periods in three selected Watersheds. In fact, the model exhibited a good association between the practical and simulated monthly average river discharge with Nash coefficient and $\mathrm{R}^{2}$. 


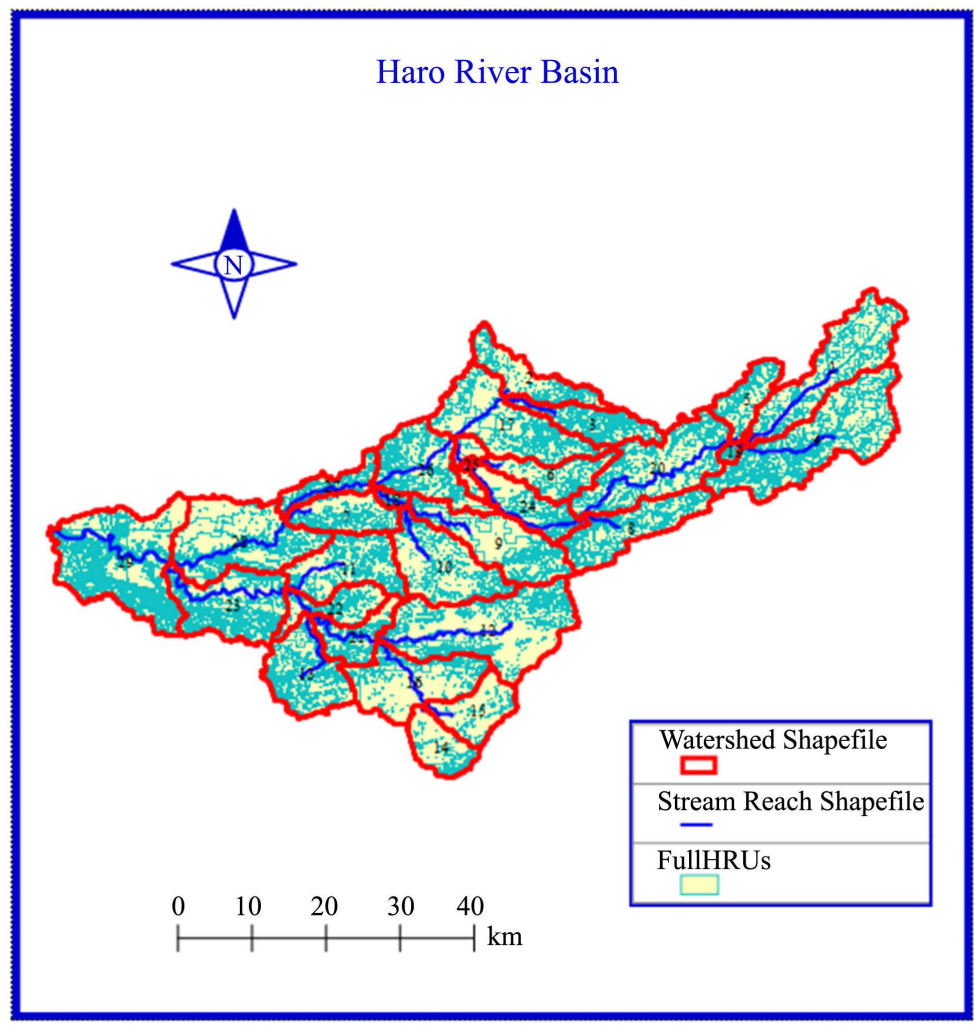

Figure 3. Watershed map of Haro River basin showing sub-basins, river and hydrological response units.

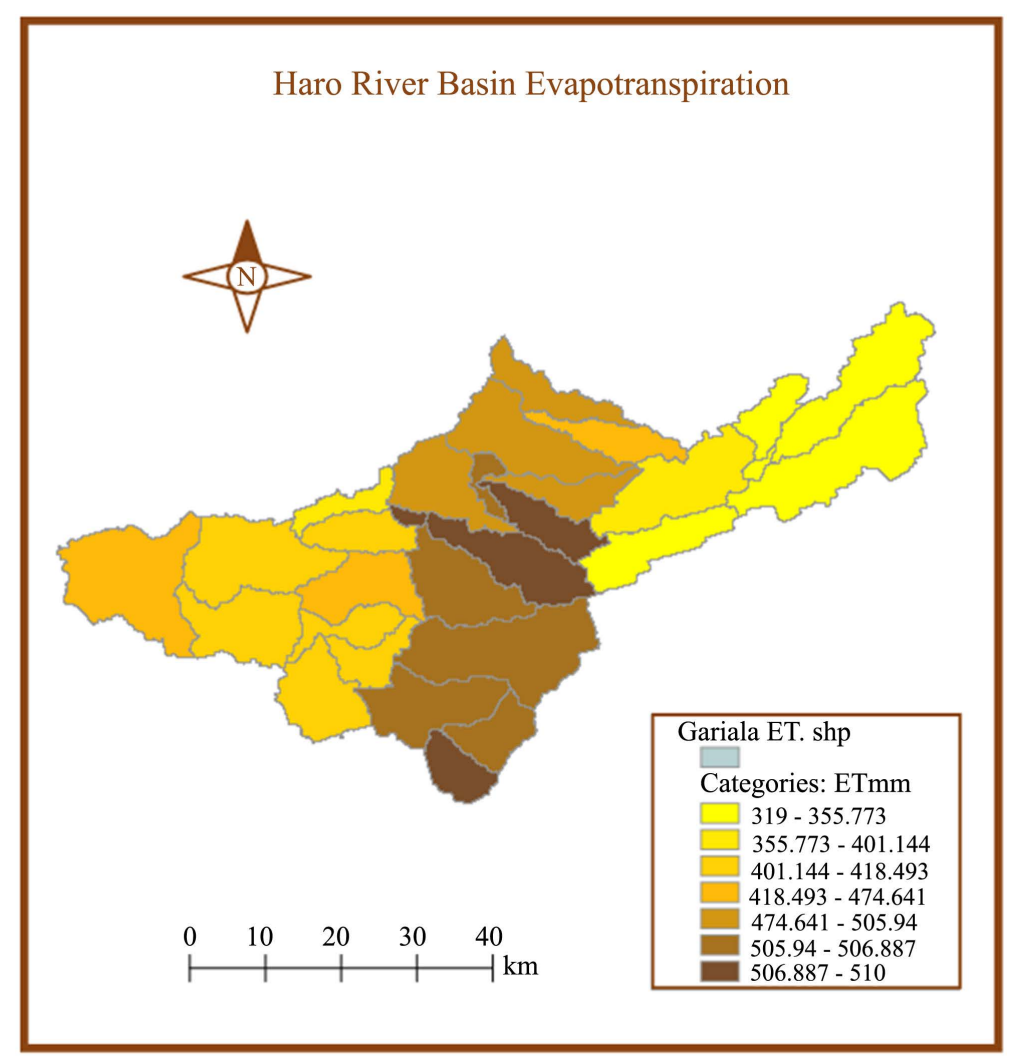

Figure 4. Long term (1979-2010) average distribution of Evapotranspiration (mm). 
Haro River Basin Ground Water

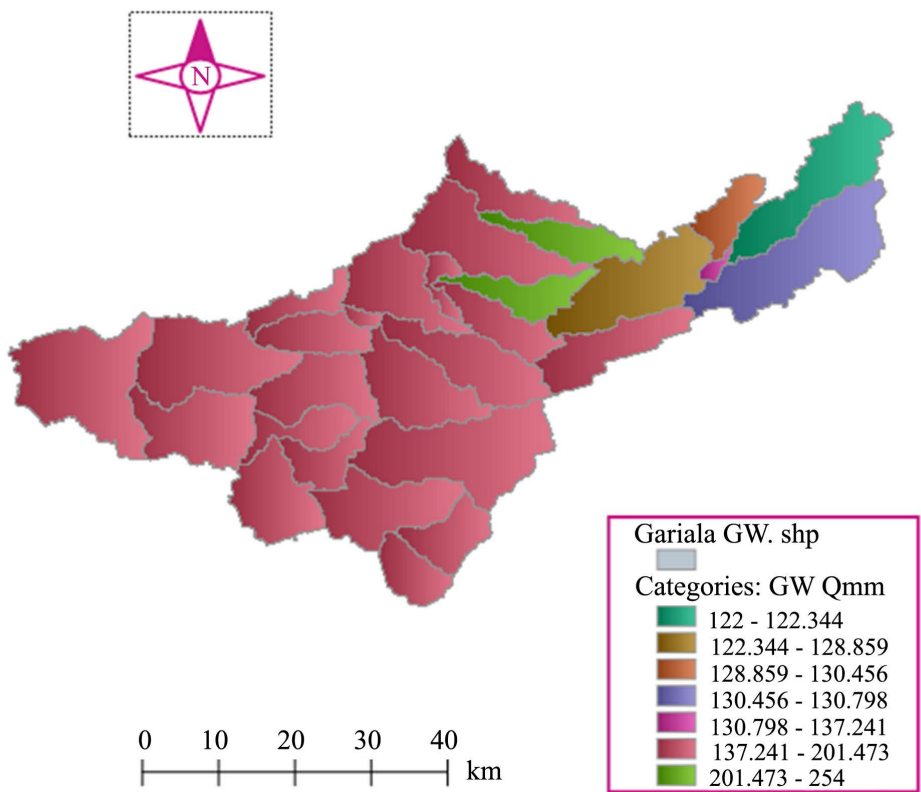

Figure 5. Long term (1979-2010) average distribution of groundwater (mm).

Haro River Basin Precipitation
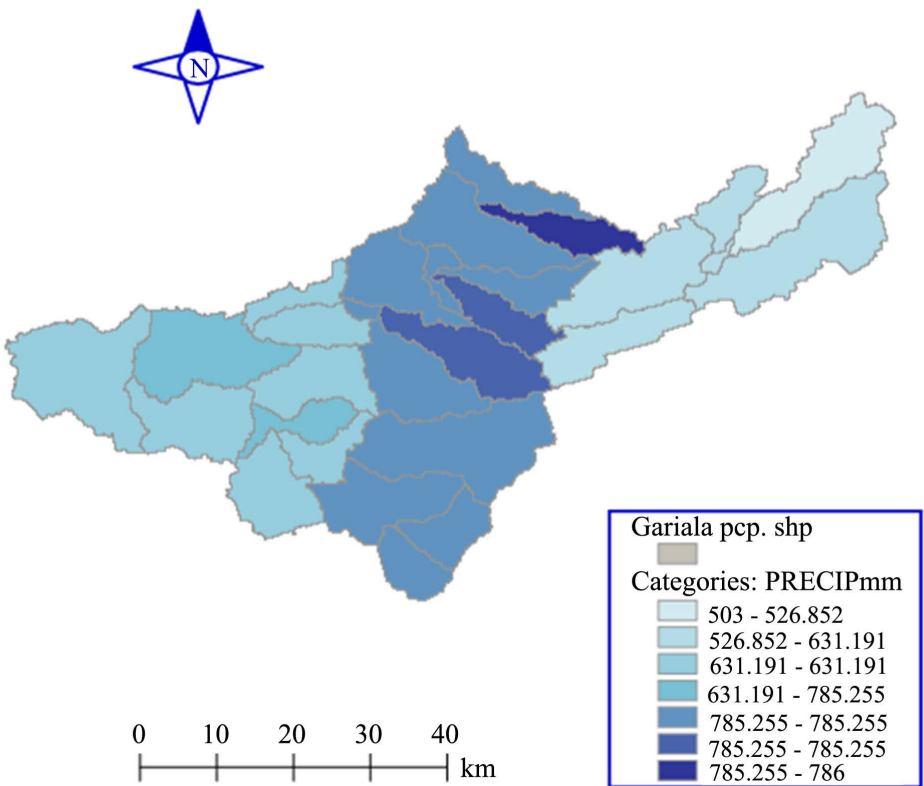

Figure 6. Long term (1979-2010) average distribution of precipitation (mm). 


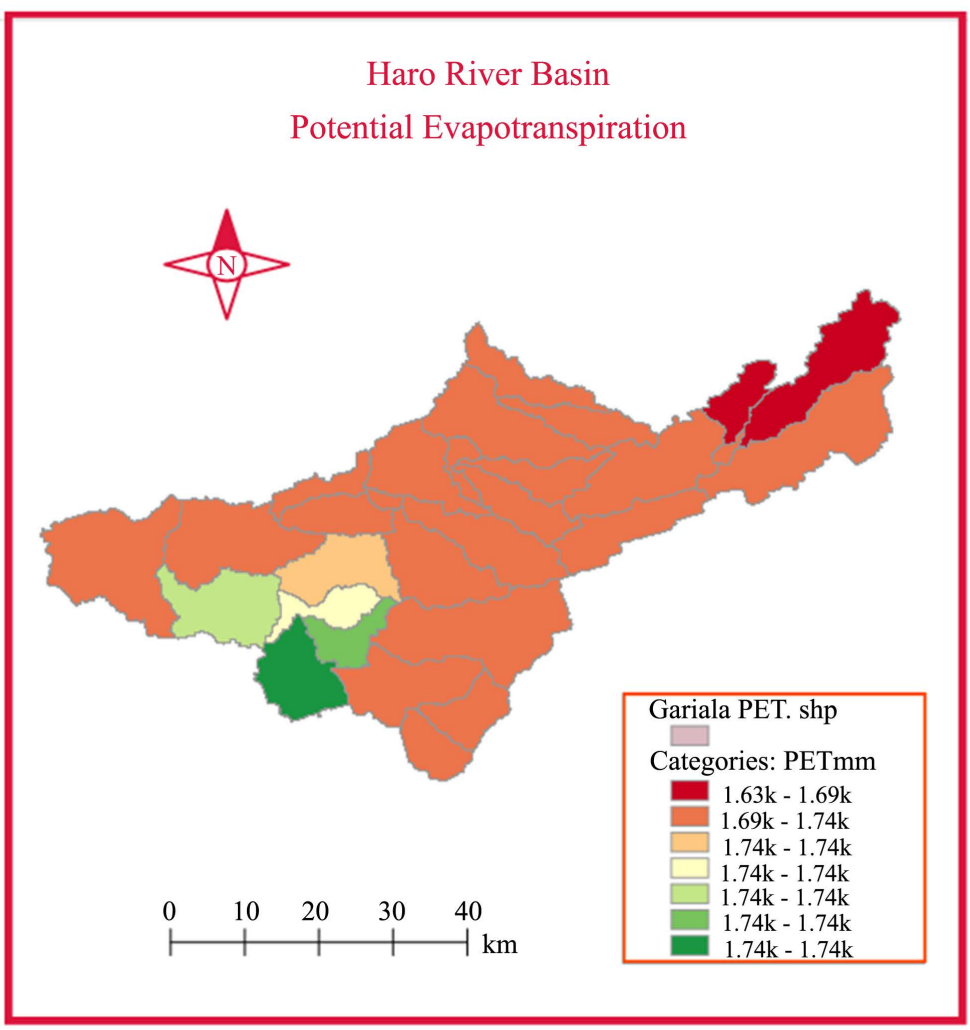

Figure 7. Long term (1979-2010) average distribution of potential evapotranspiration $(\mathrm{mm})$.

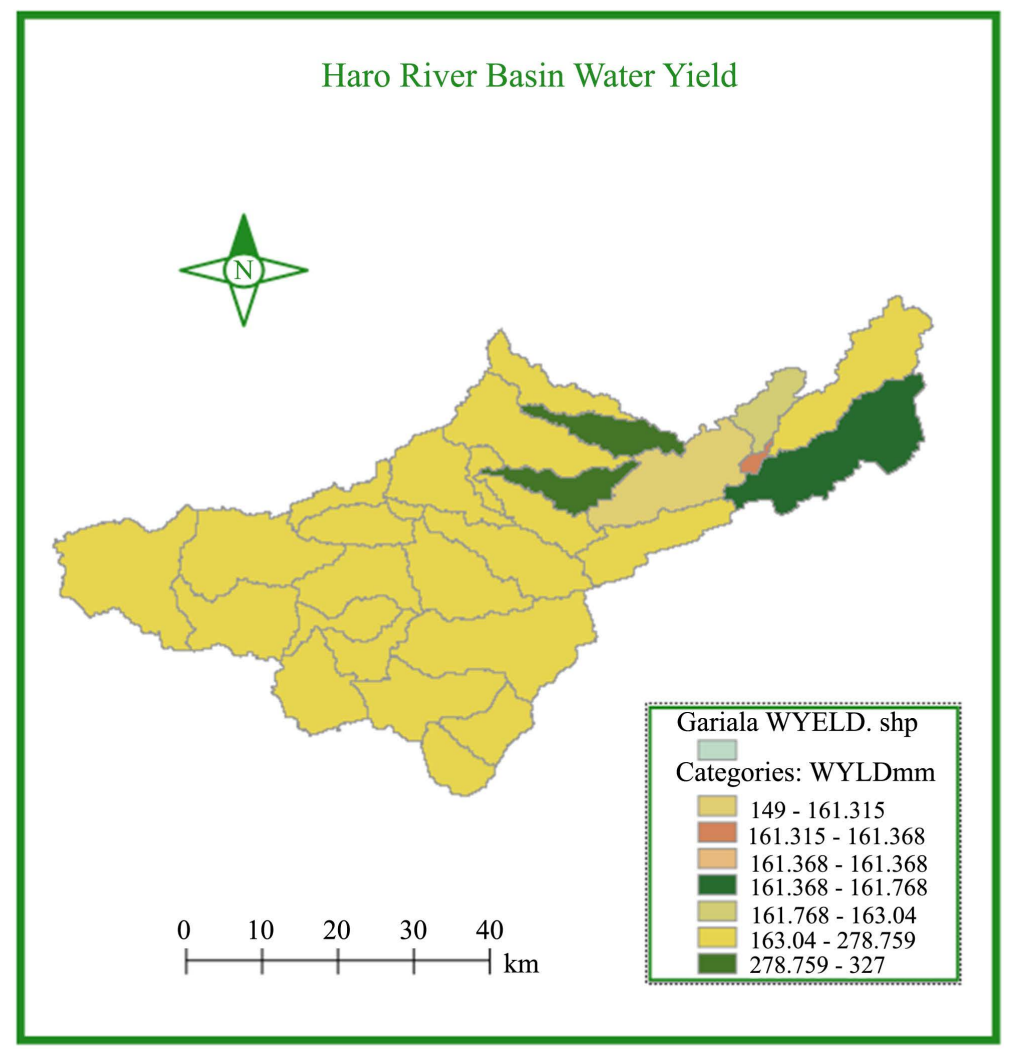

Figure 8. Long term (1979-2010) average distribution of water yield (mm). 


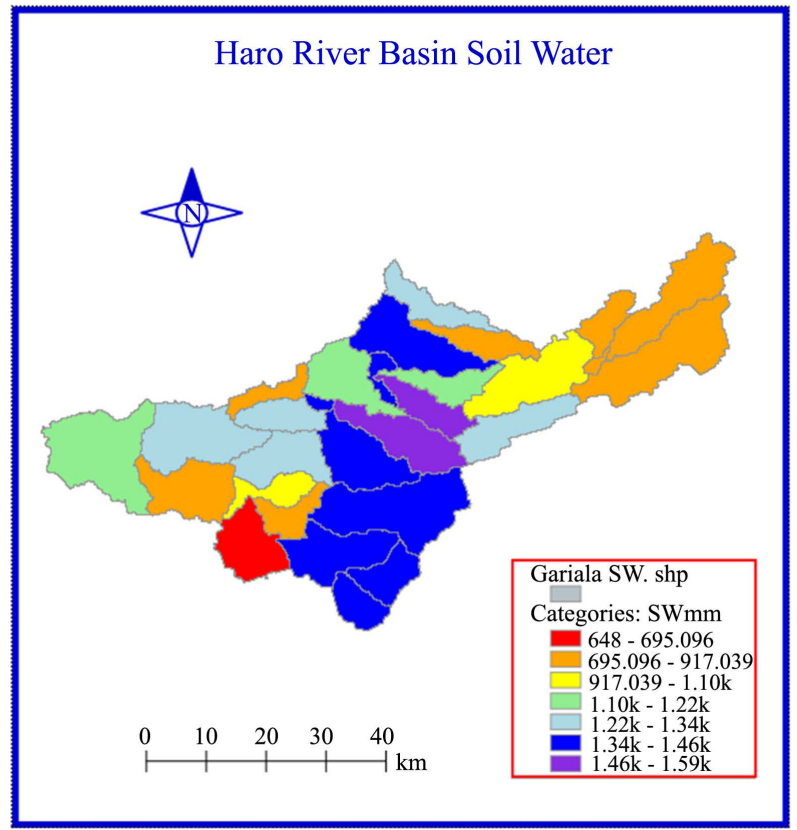

Figure 9. Long term (1979-2010) average distribution of soil water (mm).

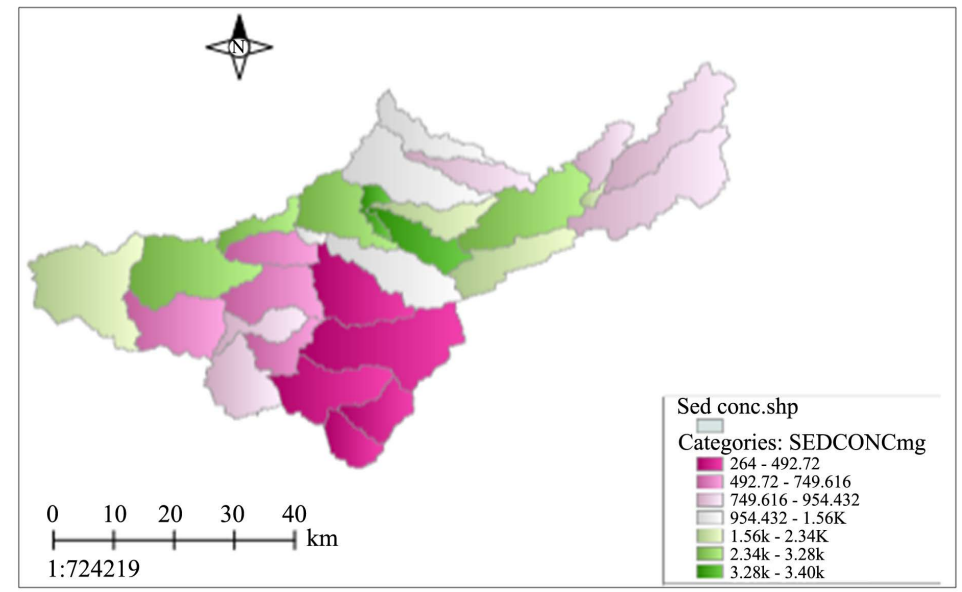

Figure 10. Long term (1979-2010) average distribution of sediment concentration (mg).

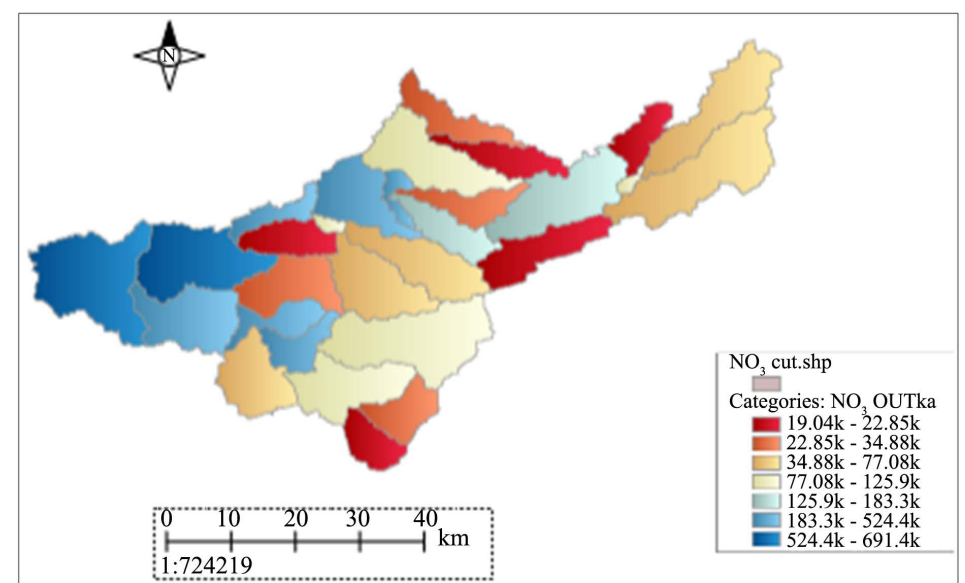

Figure 11. Long term (1979-2010) average distribution of $\mathrm{NO}_{3}(\mathrm{Kg})$. 


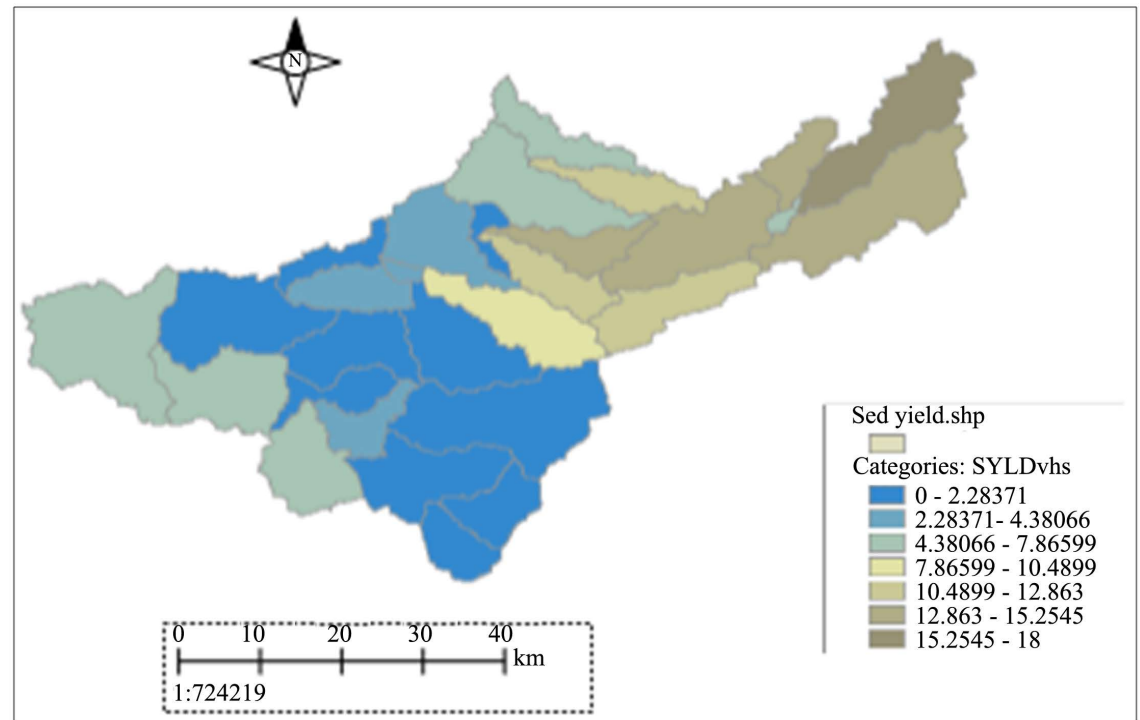

Figure 12. Long term (1979-2010) average distribution of sediment yield.

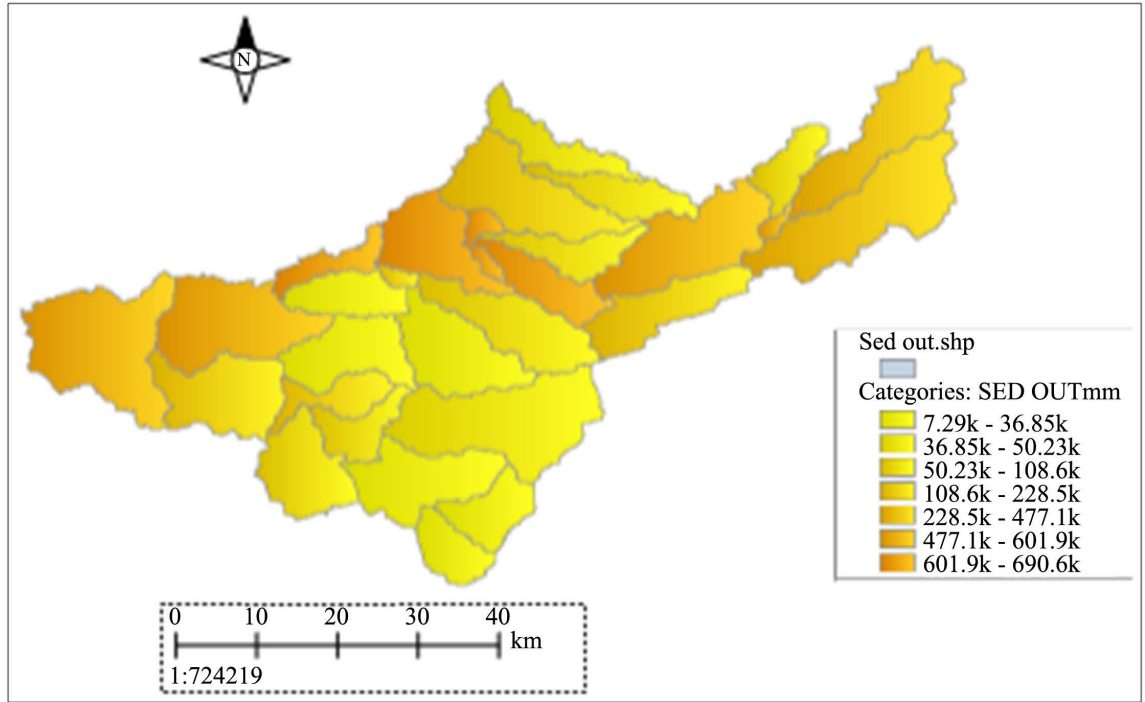

Figure 13. Long term (1979-2010) average distribution of sediment out (mg).

These outcomes justified that SWAT model could be used competently to support water management policies if it is properly calibrated.

A large $\mathrm{R}$-factor and a small $P$-factor in some stations relates to insufficient account of industrial and agricultural water use, water transfer projects or water diversion and the operation or construction of reservoirs/dams in the area. Areas with the highest activities have the largest uncertainties. The construction of reservoirs, dams, tunnels and roads can distress the local hydrology of the area for long time and can cause uncertainty of hydrological model. As the water management increased in the field of water resources, hydrological modelling is completely dependent upon the available information for the management of study area. Using the optimized ranges of parameters, Figures 3-13 are the type of maps that were produced based on long-term averages. 


\subsection{Model Analysis}

\subsubsection{Calibration and Uncertainty Analysis}

Parameter uncertainty tells us about the uncertainty of output which is based on $95 \%$ prediction uncertainty (95PPU). This 95PPU was calculated by $97.5 \%$ (U95PPU) and 2.5\% (L95PPU) levels of the cumulative distribution. Cumulative distribution was acquired by Latin hypercube sampling. Parameter uncertainty is lower down by iteration done by SUFI2.

$\mathrm{R}$-factor described the strength of calibration in a model, which is the division of average thickness of the 95PPU band and standard deviation. The basic concept of calibration in SUFI-2 is shown in Figure 14 (Leta, van Griensven et al., 2017). In this figure, single parameter value is shown by a point, which gives single model result.

For the process of calibration and validation of the SWAT Hydrological modelling, the first run was done to check the model performance and three observed discharge stations were used for calibration. After identifying, we calibrated in the next step using the discharge data of three stations on three rivers. Performance of these three stations cannot be improved by good calibration unless we know the exact nature of the observed discharge. Because, the first run showed a good prediction in terms of $P$-factor and $\mathrm{R}^{2}$ but the measure of uncertainty i.e. R-factor was to be decreased through parameter optimization in the further calibration iterations.
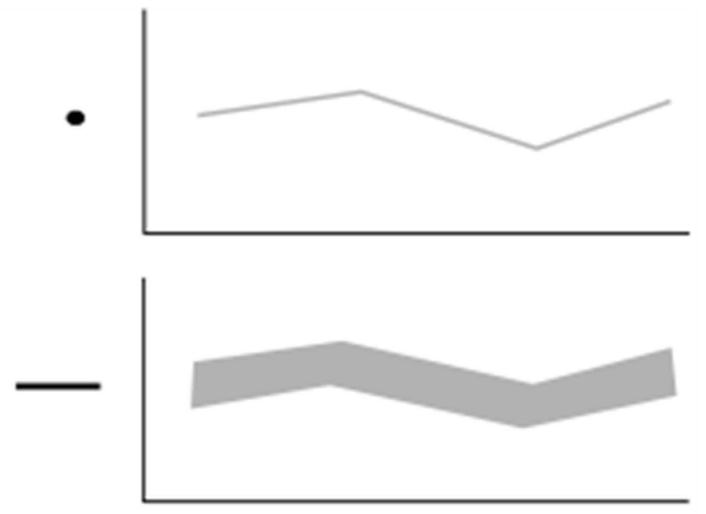

c

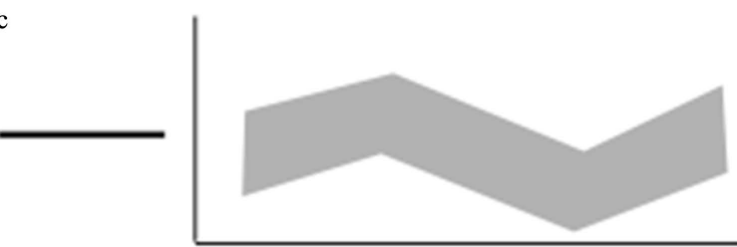

d

Figure 14. Effect of single parameter value on single response of model. 
SWAT model used input data, which have climate information to obtain results. The observed climate data of temperature gauges and rain gauge was used, the calibration results for three discharge stations produced performance. For each water region, we started with a wide range of parameter values and tried in the next calibration iterations to narrow this uncertainty. All water regions performed poor in terms of $\mathrm{R}^{2}$ and goal function. The initial $P$-factor value was satisfactory but more iteration was done in attempt to narrow uncertainty band, subsequently, resulting in small percentage of observed data within uncertainty band.

\subsubsection{Parameter Sensitivity Analysis}

In this study, the sensitive parameter ranges were identified for calibration. Seventeen parameters were found to be sensitive with values ranges from 0.001 to 0.47. These parameters were used to calibrate the model. While the remaining parameters had insignificant effect on the model, it means that any change in these parameters did not affect the calibration.

\subsubsection{Calibration and Validation of the Model}

The model was calibrated at Gariala telemetric station Placed on Haro River by Water and Power Development Authority (WAPDA) (Table 1). Monthly discharges of runoff from year 1982 to 2000 were used for calibration. After calibration, the model was validated from year 2000 to 2010 with same set of parameters listed in Table 2.

Table 1. Characteristics of Gariala telemetric stations.

\begin{tabular}{cc}
\hline Gariala Telemetric Station & \\
\hline Telemetric Station Code & $33,727,202$ \\
Latitude & 33.44 .40 \\
Longitude & 72.15 .45 \\
Elevation (m) & 329 \\
Province & Punjab \\
Installed & 1969 \\
Catchment Area $\left(\mathrm{km}^{2}\right)$ & 3056 \\
\hline
\end{tabular}

Table 2. Calibration parameter sensitive values.

\begin{tabular}{cccc}
\hline No. & Parameters & Lower and upper boundary & Fitted values \\
\hline 1 & ESCO & $0-1$ & 0.7 \\
2 & CN2 & $\pm 25 \%$ & -10 \\
3 & ALPHA_BF & $0-1$ & 0.1 \\
4 & REVAPMN & $0-500$ & 305 \\
5 & SOL_AWC & $\pm 25 \%$ & 0.3 \\
6 & GW_REVAP & \pm 0.036 & 0 \\
7 & CH_K2 & $0-5.0$ & 4.7 \\
8 & GWQMN & $0-5000$ & 118 \\
\hline
\end{tabular}


Calibration of Haro River showed increase in simulated value as compared to observed value. This is because of lack of detailed land use information, which causes error in calibration as shown in Figure 15, Figure 16 and Table 3.

Calibration of a hydrologic model alone with river discharge does not provide all components of the water balance. Therefore, it is recommended to use a calibration of multi-criteria for understanding of different component of uncertainty.

As we know that evapotranspiration and crop yield have direct relation with each other, we can use crop yield for calibration too, in order to get soil moisture, evapotranspiration, and deep aquifer recharge simulation results. We assumed

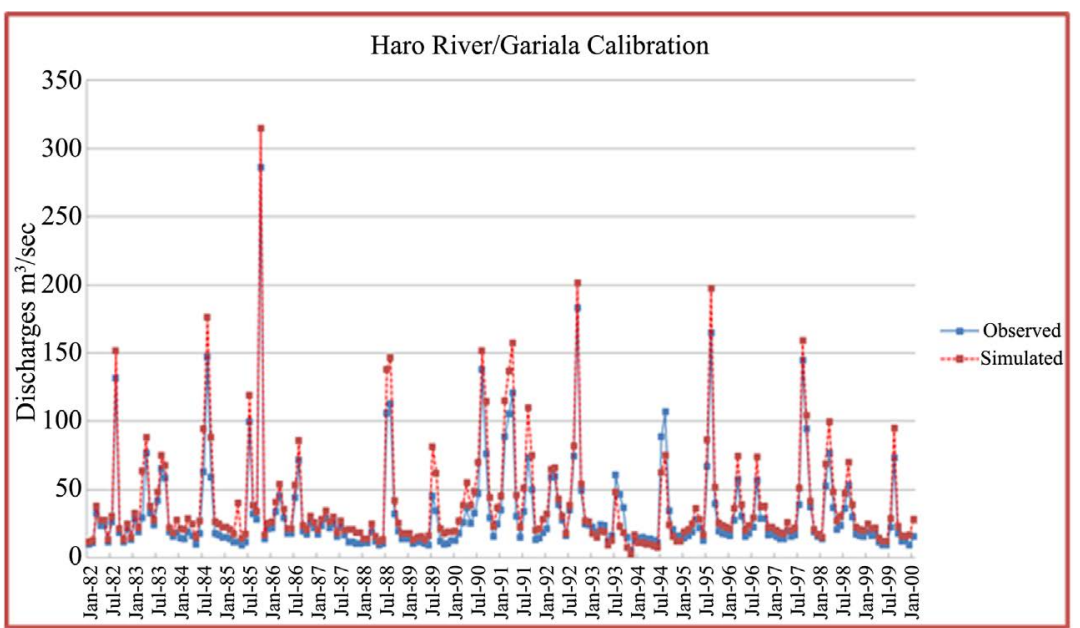

Figure 15. Calibration of model.

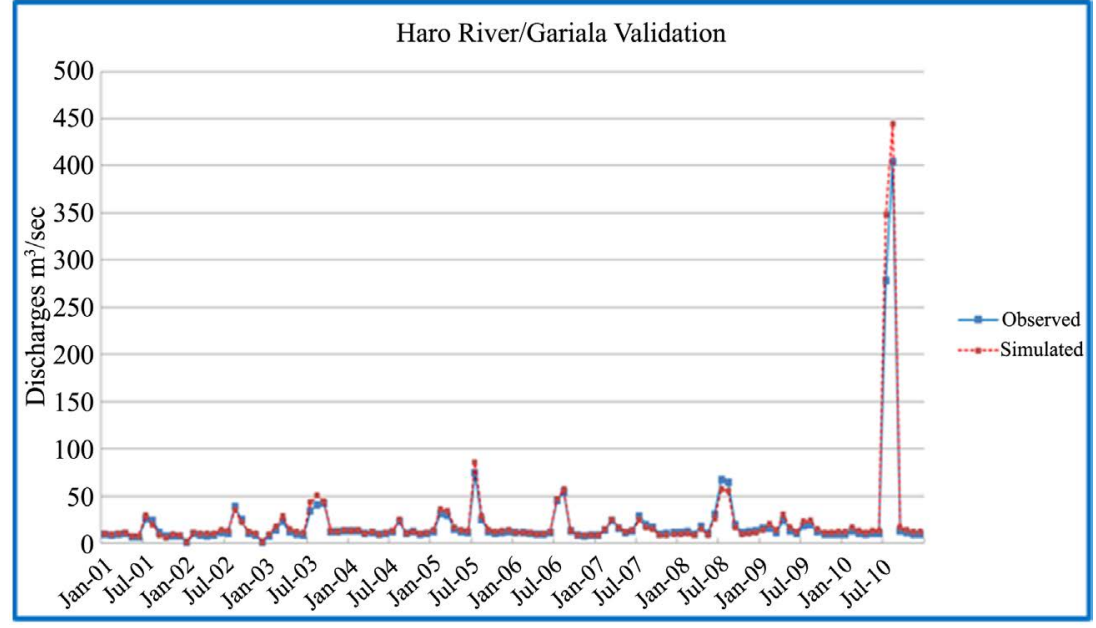

Figure 16. Validation of model.

Table 3. Calibration performance of Haro River basins while using gridded climate data, sedimentation data and discharge data as input in SWAT model.

\begin{tabular}{ccccc}
\hline River Basin & $P$ factor & R factor & $\mathrm{R}^{2}$ & Goal Function $\mathrm{BR}^{2}$ \\
\hline Haro River & 0.47 & 2.87 & 0.28 & 0.21 \\
\hline
\end{tabular}


that if crop yield is correct, then soil moisture and actual evapotranspiration were also appropriately simulated. By this, we can say that the output of deep aquifer recharge is right and based on that, water yield is also good. Transfer of water in different river systems is another source of uncertainty in hydrological model results, as it can change the hydrologic regime from its natural state. It is therefore recommended to use this data as another input in the model to improve the calibration results. In addition, it is suggested to collect agricultural management data required to model major crop yields.

To understand the effect of climate change on water resources availability and hydrological components as well as crop yield, future climate change data are also very useful and recommended to use as input in calibrated hydrological model. It is also suggested to use more refined input database as it could improve the model calibration. Such a model could be used for various water balance analysis as well as water demand and water supply analysis. By the use of improved calibrated model, climate change scenarios can be run for future management changes and their impacts on water resources quantified.

\section{Conclusion and Recommendations}

The SWAT model is applied successfully in selected watersheds of Indus Basin for predicting flows. In these sub-basins, the observed and computed flows during calibration and validation process are fairly close to each other. In 2010, Haro River basin computed peak discharge was $444 \mathrm{~m}^{3} / \mathrm{sec}$ while recorded peak discharge was $400 \mathrm{~m}^{3} / \mathrm{sec}$. The water yield Figure 8 shows large uncertainties in the water yield of water rich sub-basins. The reported uncertainty contains natural year-to-year variation due to climate as well as water abstraction and water use. It is recommended that more data regarding cropping structure, irrigation, water transfer, and reservoirs and dams be collected to produce a more realistic scenario. A precise water use data are needed to draw a more reliable picture of yield of water and deep aquifer recharge resources availability with smaller uncertainty band. An application of yield of water and deep aquifer recharge information could be to produce water scarcity maps of the study area presenting per capita water availability per year. However, water scarcity maps based only on naturalized water yield and deep aquifer recharge resources availability or water yield and deep aquifer recharge availability with a high uncertainty band might not present the real scarcity situation in these areas. Last but not the least the validation and calibration of this hydrological model were limited to dataset till 2010 due to the inaccessibility of the updated data; in future studies more recent data could be used to strengthen the calibration process the model.

\section{Acknowledgements}

Water and Power Development Authority (WAPDA) provided the data for the study. We appreciate their help and cooperation. This research received funding from National Natural Science Foundation of China (Grant No. 41671112) and 
Sichuan Province Science and Technology Plan Project Key research and development projects (Grant No. 18ZDYF0329).

\section{Conflicts of Interest}

The authors declare no conflict of interest.

\section{References}

Aquastat, F. (2011). FAO's Information System on Water and Agriculture. FAO, Food and Agriculture Organization of the United Nations.

Arnold, J. G., Moriasi, D. N., Gassman, P. W., Abbaspour, K. C., White, M. J., Srinivasan, R., Santhi, C., Harmel, R., Van Griensven, A., \& Van Liew, M. W. (2012). SWAT: Model Use, Calibration, and Validation. Transactions of the ASABE, 55, 1491-1508. https://doi.org/10.13031/2013.42256

Arnold, J. G., Srinivasan, R., Muttiah, R. S., \& Williams, J. R. (1998). Large Area Hydrologic Modeling and Assessment Part I: Model Development. Journal of the American Water Resources Association, 34, 73-89. https://doi.org/10.1111/j.1752-1688.1998.tb05961.x

Bhutta, M. N. (1999). Vision on Water for Food and Agriculture: Pakistan Perspective: Regional South Asia Meeting on Water for Food and Rural Development. New Delhi.

De Fries, R. S., Hansen, M., Townshend, J. R. G., \& Sohlberg, R. (1998). Global Land cover Classifications at $8 \mathrm{~km}$ Spatial Resolution: The Use of Training Data Derived from Landsat Imagery in Decision Tree Classifiers. International Journal of Remote Sensing, 19, 3141-3168. https://doi.org/10.1080/014311698214235

FAO/UNESCO (2003). Digital Soil Map of the World and Derived Soil Properties (Rev. 1).

Francesconi, W., Srinivasan, R., Pérez-Miñana, E., Willcock, S. P., \& Quintero, M. (2016). Using the Soil and Water Assessment Tool (SWAT) to Model Ecosystem Services: A Systematic Review. Journal of Hydrology, 535, 625-636.

https://doi.org/10.1016/j.jhydrol.2016.01.034

Hewitt, K. (2005). The Karakoram Anomaly? Glacier Expansion and the "Elevation Effect", Karakoram Himalaya. Mountain Research and Development, 25, 332-341. https://doi.org/10.1659/0276-4741(2005)025[0332:TKAGEA]2.0.CO;2

IRIN (2001). Pakistan: Intruding Sea Water Threatens Indus River. UN Office for the Co-Ordination of Humanitarian Affairs Integrated, Regional Information Networks Article.

Jarvis, A., Reuter, H. I., Nelson, A., \& Guevara, E. (2008). Hole-Filled SRTM for the Globe Version 4. The CGIAR-CSI SRTM 90m Database. http://srtm.csi.cgiar.org

Johnston, J. M., McGarvey, D. J., Barber, M. C., Laniak, G., Babendreier, J., Parmar, R., Wolfe, K., Kraemer, S. R., Cyterski, M., \& Knightes, C. (2011). An Integrated Modeling Framework for Performing Environmental Assessments: Application to Ecosystem Services in the Albemarle-Pamlico Basins (NC and VA, USA). Ecological Modelling, 222, 2471-2484. https://doi.org/10.1016/j.ecolmodel.2011.03.036

Kahlown, M. A., Raoof, A., Zubair, M., \& Kemper, W. D. (2007). Water Use Efficiency and Economic Feasibility of Growing Rice and Wheat with Sprinkler Irrigation in the Indus Basin of Pakistan. Agricultural Water Management, 87, 292-298.

https://doi.org/10.1016/j.agwat.2006.07.011

Leta, O. T., van Griensven, A., \& Bauwens, W. (2017). Effect of Single and Multisite Calibration Techniques on the Parameter Estimation, Performance, and Output of a SWAT Model of a Spatially Heterogeneous Catchment. Journal of Hydrologic Engineering, 22, 
Article ID: 05016036. https://doi.org/10.1061/(ASCE)HE.1943-5584.0001471

Linn, J. F. Pakistan-Salinity Control and Reclamation (SCARP) Transition Pilot Project.

Mishra, S. K., \& Singh, V. P. (2013). Soil Conservation Service Curve Number (SCS-CN) Methodology. Berlin: Springer Science \& Business Media.

NCDC National Climatic Data Center.

NESPAK (1997). Flood Early Warning System Manual for Indus Basin (p. 425). Lahore: National Engineering Services Pakistan (NESPAK).

Seeber, L., \& Gornitz, V. (1983). River Profiles along the Himalayan Arc as Indicators of Active Tectonics. Tectonophysics, 92, 335-367. https://doi.org/10.1016/0040-1951(83)90201-9

Snow, S. (1990). Ice Hydrology Project, Upper Indus River Basin (p. 179). WAPDAIDRC-Wilfrid Laurier University.

SRTM DEM (2004). Data from International Centre for Tropical Agriculture (CIAT). CGIAR-CSI SRTM 90m. Database. http://srtm.csi.cgiar.org

Trabucco, A., \& Zomer, R. (2010). Global Soil Water Balance Geospatial Database. CGIAR Consortium for Spatial Information. http://cgiar-csi.org

United Nations (2009). Population Division of the Department of Economic and Social Affairs.

WAPDA (1990). Water and Power Development Authority, Water Sector Investment Planning Study (WSIPS) (p. 5). Lahore: Federal Planning Cell.

World Bank (2012). http://data.worldbank.org/country/pakistan

Zaman, S. B., \& Ahmad, S. (2009). Salinity and Waterlogging in the Indus Basin of Pakistan: Economic Loss to Agricultural Economy (pp. 1, 4-8). Managing Natural Resources for Sustaining Future Agriculture. 